\title{
Sustainability and conservation
}

I work in conservation. Ecosystem collapse would end human civilization as surely as nuclear war or global warming. Natural sciences show why we need to conserve biodiversity. Social sciences show that conservation needs people for economic and political support. In an attempt to address these complex issues, I have moved from ecological research to industry, to law, to trade disputes, to ecosystem services markets, to ecotourism, and now to psychology. How can we harness human desires, and create social machines and political institutions, to protect planetary ecosystems? Science leads the search for new ideas and understanding.

Ralf C. Buckley

Griffith School of Environment, Griffith University, Gold Coast, QLD 4222, Australia.

Email: r.buckley@griffith.edu.au 